\title{
Water limitation prevails over energy in European diversity gradients of sheetweb spiders (Araneae: Linyphiidae)
}

\author{
Sabrina Kumschick ${ }^{\mathrm{a}, *}$, Martin H. Schmidt-Entling ${ }^{\mathrm{a}}$, Sven Bacher ${ }^{\mathrm{b}}$, Thomas Hickler ${ }^{\mathrm{c}}$, \\ Wiebke Entling ${ }^{\mathrm{a}}$, Wolfgang Nentwig ${ }^{\mathrm{a}}$ \\ ${ }^{a}$ Community Ecology, Institute of Ecology and Evolution, University of Bern, Baltzerstrasse 6, 3012 Bern, Switzerland \\ ${ }^{\mathrm{b}}$ Department of Biology, Ecology and Evolution Unit, University of Fribourg, Chemin du Musée 10, 1700 Fribourg, Switzerland \\ ${ }^{\mathrm{c}}$ Department of Physical Geography and Ecosystems Analysis, University of Lund, Sölvegatan 13, 22362 Lund, Sweden
}

\begin{abstract}
Across large spatial scales, species richness in many taxa is mainly determined by climatic variables. However, some of the mechanisms behind large-scale patterns of species richness and abundance are expected to act on the community level, and on a smaller scale than the resolution of the data commonly used for deriving these patterns. We studied the distribution of sheetweb spiders (Araneae: Linyphiidae) across Europe using both standardised samples from local habitats and large-scale inventories. In the first approach, we analysed species and individual numbers from standardised pitfall traps from 17 locations distributed from northern Sweden to Spain and Greece. We also calculated Simpson indices to correct for different activity densities. Additionally, we analysed whether diversity of sheetweb spiders is sensitive to habitat type. In the second approach, we investigated the known sheetweb spider species richness of European countries and large islands. In both datasets, species richness of sheetweb spiders reached a maximum at about $55^{\circ} \mathrm{N}$ and declined towards the Mediterranean and the Arctic. In addition, species richness decreased from western (maritime) to eastern (continental) regions. Also Simpson diversity showed a hump-shaped relation to latitude, and was the only variable influenced by habitat type. In contrast to species richness and diversity, activity density increased monotonously with latitude. Towards the north, sheetweb spiders are likely limited by energy availability, towards the south, water limitation as well as bottom-up and top-down community interactions may reduce sheetweb spiders. Accordingly, their diversity does not follow the pattern of vertebrates, large insects and aquatic organisms, which depend more strongly on energy availability.
\end{abstract}

\section{Zusammenfassung}

Über grosse räumliche Skalen ist Artenreichtum in vielen Taxa hauptsächlich von klimatischen Variablen bestimmt. Jedoch kann erwartet werden, dass sich einige kausale Mechanismen auf der Ebene von Artengemeinschaften abspielen und somit auf einer kleineren Skala als durch die Daten repräsentiert wird, welche üblicherweise zum Herleiten dieser Muster untersucht werden. Wir haben die Verteilung von Linyphiiden (Araneae: Linyphiidae) in Europa untersucht und haben dafür standardisierte Erfassungen aus lokalen Habitaten und grossräumige

\footnotetext{
*Corresponding author. Tel.: + 41316313034 ; fax: + 41316314888.

E-mail address: sabrina.kumschick@iee.unibe.ch (S. Kumschick).
} 
Bestandesaufnahmen benutzt. Im ersten Ansatz haben wir Arten- und Individuenzahlen aus standardisierten Bodenfallen von 17 Standorten untersucht, die sich vom nördlichen Schweden bis nach Spanien und Griechenland verteilten. Mit Simpson Indices haben wir für unterschiedliche Aktivitätsdichten korrigiert. Zusätzlich haben wir untersucht, ob die Diversität von Linyphiiden auf den Habitattyp reagiert. Im zweiten Ansatz haben wir den bekannten Artenreichtum der Linyphiiden aus europäischen Ländern und von grossen Inseln verrechnet. In beiden Datensätzen erreichte der Artenreichtum der Linyphiiden ein Maximum um $55^{\circ} \mathrm{N}$ und nahm zum Mittelmeerraum und zur Arktis ab. Zusätzlich nahm der Artenreichtum von westlichen (maritimen) zu östlichen (kontinentalen) Regionen ab. Auch die Simpson-Diversität zeigte eine ähnliche Beziehung zum Breitengrad mit einem Maximum in Mitteleuropa und war die einzige Variable, welche vom Habitattyp beeinflusst wurde. Im Gegensatz zu Artenreichtum und Diversität stieg die Aktivitätsdichte monoton mit den Breitengraden an. Gegen Norden sind Linyphiiden wahrscheinlich durch Energie limitiert, gegen Süden begrenzen eher Wassermangel sowie bottom-up und top-down Interaktionen innerhalb der Gemeinschaften. Daher verhält sich die Diversität der Linyphiiden nicht entsprechend den üblichen Diversitätsmuster von Vertebraten, grossen Insekten und aquatischen Organismen, welche stärker von Energie abhängen.

Keywords: Latitude; Biodiversity; Species richness; Simpson index; Activity density

\section{Introduction}

On large spatial scales, species richness is largely determined by latitudinal gradients of climate (e.g., Hawkins, Albuquerque, Araújo, Beck, Bini et al. 2007; von Humboldt 1808). Generally, species richness increases from the poles to the equator, i.e., from arctic to tropical climates. This applies to most taxonomic groups and to organisms occupying terrestrial, freshwater and marine environments. One of the most common explanations for an increase in species richness with temperature and energy-linked productivity is the "more individuals hypothesis" (Mönkkönen, Forsman, \& Bokma 2006). It assumes that increased energy availability leads to an increased density of consumers, which translates into higher species richness because more species can obtain a population size that exceeds some minimal viable size. However, some taxa do not conform to this generality. Aphids, bees, sawflies and parasitic hymenopterans, for example, are not most species rich in tropical regions (Gaston \& Spicer 1998).

Most of the existing studies on large-scale patterns of biodiversity deal with atlas data. With this kind of data, one can study regional richness patterns. But atlas data do not provide information on densities, which is crucial if certain hypotheses on the mechanisms generating biodiversity patterns are to be tested. Only direct field sampling can provide this information. Another advantage of field sampling is that catches comprise species which co-occur in a specific habitat. In contrast, atlas data are summed over large spatial scales and thus include species that may not necessarily co-occur in the same habitat. Thus, sampled data reflect local phenomena such as competition and niche differentiation better than atlas data. However, most field sampling studies were conducted over a relatively small spatial scale. For this reason, we combine large-scale data and local habitat samples to explore potential mechanisms behind continental diversity patterns.

Spider species richness at a continental scale in Europe is negatively correlated with latitude (Finch, Blick, \& Schuldt 2008). However, this overall pattern may become quite different when broken down to family level. Concerning sheetweb spiders, Bristowe (1939) already observed that they are the dominant spider family in terms of species richness and overall density in temperate regions. Enders (1975), using Bristowe's dataset, proposed this pattern to be a result of exploitative competition between jumping spiders (Salticidae) and sheetweb spiders. Jocqué (1984) rejects this hypothesis and states that sheetweb spiders are more likely to be limited by interference competition from other groups, such as ants, which are more numerous in tropical regions. These two studies use the dataset published by Bristowe (1939), who analysed the percentage of the total spider fauna represented by sheetweb spiders on country level. However, since the total species richness of spiders varies greatly between countries, absolute numbers of sheetweb spider species (corrected for area) are more relevant to the proposed mechanisms than percentages. We were thus interested to find out whether the pattern found by Bristowe holds for species richness of sheetweb spiders, diversity and activity density on the level of countries and assemblages.

To be able to also take into account locally occurring aspects and regional phenomena, we used the following two approaches: First, we employed a standardised sampling program across Europe, and compared the influence of climate and space on sheetweb spiders across different habitat types. Second, we analysed 
spider inventories from 40 European countries and large islands.

Based on Bristowe (1939) and his successors, we hypothesised that sheetweb spider diversity increases from southern to northern Europe. We also expect, that sheetweb spider diversity declines again beyond some certain latitude, because sheetweb spiders are absent from the high arctic. Thus, we expect a hump-shaped relationship between richness and activity density with latitude. Furthermore, we explore the influence of habitat type on local sheetweb spider assemblages and expect that frequently disturbed habitats such as arable land have lower species richness than more natural habitats as for instance forest.

\section{Materials and methods}

\section{Study organisms}

We focus on the family of sheetweb spiders (Linyphiidae). This is the most common and species-rich spider family in Europe with 1168 species (Fauna Europaea, version 1.3). Worldwide, they include about 4300 described species in 578 genera.

\section{Field sites}

For the first part of this project, we sampled spiders at 17 field sites (Fig. 1). Fourteen of the sites belonged to the ALARM (Settele, Hammen, Hulme, Karlson, Klotz et al. 2005) field site network, and three sites (Bern, Silkeborg, Vienna) were added to fill geographic gaps. These sites enabled us to employ a standardised sampling procedure on a continental scale. At each field site, two habitats were selected, which were either arable land, grassland, scrubland or forest (Fig. 1). Two sites had only one habitat, Abisko had only scrubland due to the absence of agriculture, and in Lesvos only grassland was available, so in total, we investigated 32 habitat samples. The four studied habitat types represent a gradient of disturbance and succession age. To achieve the best possible comparability between sites, we mailed pitfall trap material and preservation liquid to the respective field site managers, and specified a standardised trap setup in an enclosed manual.

Trapping took place in year 2006 and started 5 days after the beginning of the vegetation period as defined by Rötzer and Chmielewski (2001). This varied from late March in the Mediterranean part of Europe to June in the northernmost field site of Abisko, Sweden. This time was chosen in order to let the sampling period coincide with the time of highest spider activity at all locations (Cardoso, Silva, De Oliveira, \& Serrano 2007) to ensure adequate sampling.

Within each habitat, eight pitfall traps were installed along a transect $20 \mathrm{~m}$ from the edge. Traps were separated by $3 \mathrm{~m}$ from each other, which is sufficient to avoid interference between traps (M.H. SchmidtEntling, unpublished data). Plastic beakers of $7 \mathrm{~cm}$ diameter and $8 \mathrm{~cm}$ height were used as traps, and dug

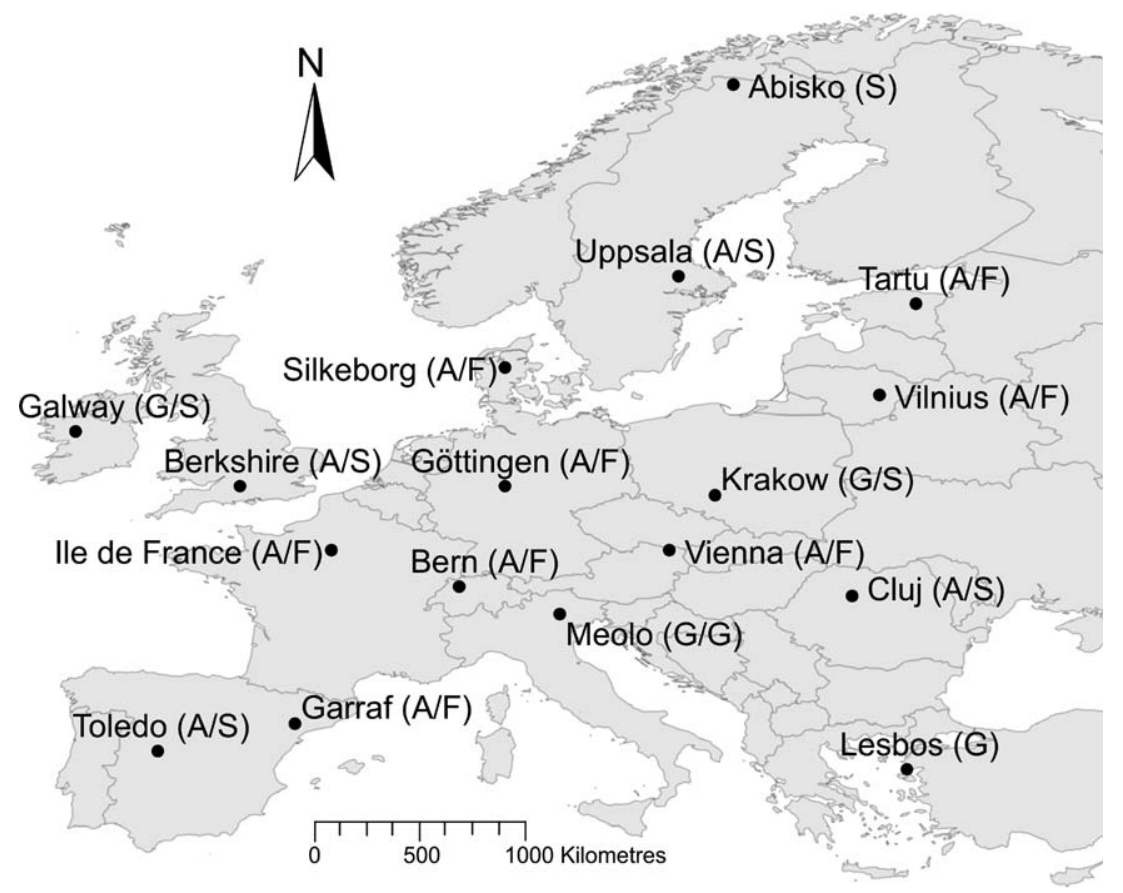

Fig. 1. Distribution of the sampling sites across Europe. The habitat type(s) sampled at each site are given in parentheses. $\mathrm{F}=$ forest, $\mathrm{S}=$ scrubland, $\mathrm{G}=$ grassland and $\mathrm{A}=$ arable land . 
into the soil so that the upper borders of the traps were at the level of the soil surface. Traps were filled with $100 \mathrm{ml}$ of a $4 \%$ formaldehyde solution as trapping liquid, with a few drops of sodium dodecyl sulphate solution as detergent. After 2 weeks of trap exposure, traps were emptied and closed for 2 weeks. Then, a second period of collecting followed, a second pause of two weeks, and finally a third collecting period of 2 weeks. So the total trapping effort was 42 days $\times 8$ traps $=336$ trapping days/site. The contents of all traps were shipped back to Bern. We determined adult sheetweb spiders sampled in the field sites to species level following Nentwig, Hänggi, Kropf, and Blick (2003) and relevant literature mentioned there. The nomenclature follows Platnick (2008). Species and individual numbers were pooled over the entire sampling period.

\section{Country inventories}

For the second dataset, we compiled the number of sheetweb spider species known from 40 European countries and large islands (van Helsdingen 2007). We excluded biogeographical extremes that are far away from the mainland and/or lie in another bioclimatic zone (Canary Islands, Cyprus, Turkey, Faroe Islands, Azores, Madeira, Selvagens Island, Franz Josef Land, Novaya Zemlya, Svalbard and Jan Mayen) and countries/islands smaller than $500 \mathrm{~km}^{2}$ (Greek islands except Crete, Monaco, Gibraltar, Liechtenstein, Channel Island, Malta, Andorra). Moreover, we excluded three countries (Luxemburg, Albania, BosniaHerzigowina) which showed significant deviations from the $\log$ (species richness)/log (area) - relationship considering all spider species $(90 \%$ confidence level), indicating that the known spider fauna of these countries is incomplete.

\section{Data analysis}

\section{Field sites}

We considered a number of variables that potentially explain variation in sheetweb spider species richness or activity density. Habitat type was a nominal variable with the four categories forest, scrubland, grassland and arable land. As spatial variables we included a quadratic response surface to test for non-linear relationships comprising latitude, square of latitude, longitude and its square and latitude time's longitude. Finally, we collected data for the climatic variables annual mean temperature, temperature difference between the hottest and the coldest month as a measure of continentality, annual precipitation in $\mathrm{mm}$ and cloud cover in percent.
Then we modelled a number of additional variables. Soil water content (WC) was expressed as the fraction of available water-holding capacity in the top $50 \mathrm{~cm}$ of the soil, averaged over the growing season (daily temperatures $>5{ }^{\circ} \mathrm{C}$ ). The number of growing degree days (GDD) (above $5^{\circ}$ ) over the growing season was used as a measure of the thermal energy available during the year; this measure is highly correlated with the tree line and the northern distribution limit of many trees (Sykes, Prentice, \& Cramer 1996). Actual evapotranspiration (AET) is a measure of water-energy balance closely associated with plant productivity, and potential evapotranspiration (PET), a measure of ambient or atmospheric energy. For all climatic variables, we used averaged yearly values of 2005 and 2006 and the longterm average from 1990 to 2006. For 1990-2002, climatic variables were extracted from a gridded dataset of observed climate with a resolution of $0.5^{\circ}$ (Mitchell \& Jones 2005). Climate data from 2003 to 2006 were obtained from weather stations within $10 \mathrm{~km}$ of the respective site. Soil water content, actual and potential evapotranspiration were calculated with the LPJGUESS ecosystem model (Smith, Prentice, \& Sykes 2001), parameterised for simulating the potential natural vegetation of Europe (Hickler, Fronzek, Araújo, Schweiger, Thuiller et al. 2009; supplementary information).

To extract the main environmental gradients for the field site study, we performed a principal component analysis (PCA) on the environmental variables mentioned above using Canoco for Windows Version 4.5 (Ter Braak \& Smilauer 2002). To identify to which axes the different environmental variables belong, we arbitrarily chose a lower limit of 0.6 loadings (absolute value), because this differentiated best between the first two PC axes.

Trapping success was on average 23.22 traps (of 24 traps set) per site. Maximally, there were three traps missing so we did not correct for missing traps. We checked for completeness of samples using the abundance-based coverage estimator in EstimateS 8.0 (Colwell, Mao, \& Chang 2004). Sample completeness was not correlated to the measured environmental variables (data not shown). As diversity measures that are independent of the number of sampled individuals, we calculated the Simpson diversity index (Lande 1996) and individual-based rarefaction (Colwell, Mao, \& Chang 2004). Because the results of Simpson diversity highly resembled the rarefaction, we only display Simpson diversity.

We tested for influences of habitat type and quadratic response surface of latitude and longitude on $\log _{10^{-}}$ transformed species richness (number of species sampled per habitat), activity density (number of individuals sampled per habitat) and the Simpson index using general linear models. All analyses were done with the statistical software $\mathrm{R}$ (version 2.3.1; R Development 
Core Team 2006) by first fitting a linear regression model. The number of incidence groups required for the model was optimised with the $\mathrm{R}$ package MASS (Venables \& Ripley 2002) using Akaike's Information Criterion (AIC; Stephens, Buskirk, \& Martínez Del Rio 2006), as a balance between goodness of fit and complexity of the model (number of parameters). Afterwards, we carried out an ANOVA (error type II) of the reduced model with the R package car (Fox 2009) for estimating the overall effect of categorical variables with more than two levels.

To compare the influences of the different habitat types, we performed Tukey HSD tests on the residuals of species richness, Simpson indices and activity densities after accounting for all the other variables in the final model except habitat type. The residuals were used to only account for the variation in the data after correcting for the influence of the other variables. This was also done with the software R.

\section{Countries}

In the second investigation, the areas of European countries and large islands were calculated with ArcMap (version 9.1, ESRI Inc., Redlands, CA, USA). As corresponding latitude and longitude we took the midpoint of the countries/islands. $\log _{10}$-transformed species richness was then analysed with $\log _{10}$-transformed area, latitude, longitude and quadratic response analogous to the field site data.

\section{Results}

\section{Field sites}

\section{Environmental variables}

The first two axes of the PCA represented energyrelated variables (PC1) and water-related variables (PC2), respectively. $\mathrm{PC} 1$ had an eigenvalue of 0.83 and represented latitude (Y) and cloud cover (CC) on the positive side and temperature (T), potential evapotranspiration, actual evapotranspiration and growing degree days on the negative side (Fig. 2; for joint plot, see Appendix A). The second axis $(\mathrm{PC} 2$; eigenvalue $=0.11)$ was composed of longitude (X) and the difference between the warmest and coldest month (TDif) on the negative side, and of water content and partly precipitation (PP) on the positive side. For further analysis, we used one variable each representing the first and second principal component, respectively, namely latitude and longitude. In addition, habitat types were retained in the analysis as they were not represented on the first two principal components (loadings <0.6). We used these three variables - longitude, latitude and habitat type for all further analysis concerning the sampled data.

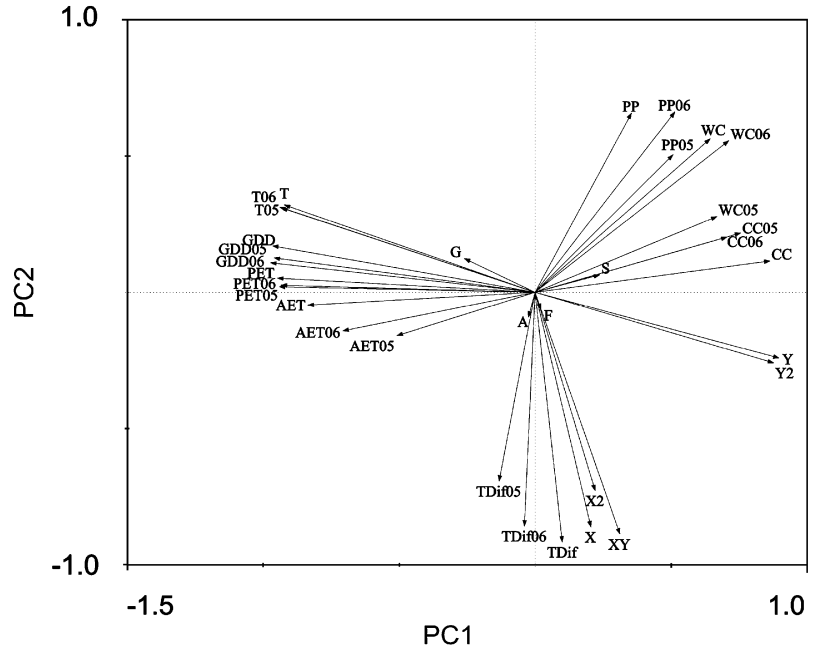

Fig. 2. PCA showing the grouping of environmental variables at the sampled field sites on the first and second axis. The first axis $(\mathrm{PC} 1)$ represents energy with the variables latitude $(\mathrm{Y})$, square of latitude (Y2) and cloud cover (CC05, CC06, CC) in one direction and mean annual temperature of 2005, 2006 and long-term temperature (T05, T06, T), growing degree days (GDD05, GDD06, GDD), potential (PET05, PET06, PET) and partly actual evapotranspiration (AET05, AET06, AET) in the opposite direction; the second axis (PC2) represents continentality with longitude (X) and square of longitude (X2), latitude times longitude (XY), temperature difference between the hottest and the coldest month of 2005, 2006 and long term (TDif05, TDif06, TDif) in the one and water content (WC05, WC06, WC) and partly precipitation (PP05, PP06, PP) the other direction. Habitat types are arable land (A), grassland (G), scrubland (S) and forest (F).

\section{Spider assemblages}

The traps yielded 11,866 spider individuals of 35 families. Of these, 5223 were adult sheetweb spiders (Linyphiidae), which belonged to 147 (morpho-) species.

As expected, species richness of sheetweb spiders showed a hump-shaped relationship to latitude with both, latitude $\left(F_{1,25}=17.80, p<0.001\right)$ and its square $\left(F_{1,25}=13.80, \quad p=0.001\right)$, being highly significant (Fig. 3A). Maximal richness was reached at $57.33^{\circ} \mathrm{N}$. There was a linear decrease of richness from maritime to continental regions $\left(F_{1,25}=5.63, p=0.026\right)$. The influence of habitat type on species richness was only marginally significant $\left(F_{3,25}=2.74, p=0.065\right)$. In pairwise comparisons, we found no significant differences.

Similar to species richness, Simpson diversity of the sampled sheetweb spider assemblages showed a humpshaped relationship to latitude (linear term: $F_{1,25}=6.96$, $p=0.014 ;$ quadratic term: $F_{1,25}=5.03, p=0.034$ ) (Fig. 3B) with a maximum at $58.83^{\circ} \mathrm{N}$. In contrast to species richness, Simpson diversity showed no significant relation to longitude $\left(F_{1,25}=2.48, p=0.128\right)$. The habitat types had significantly different levels of 
(A)

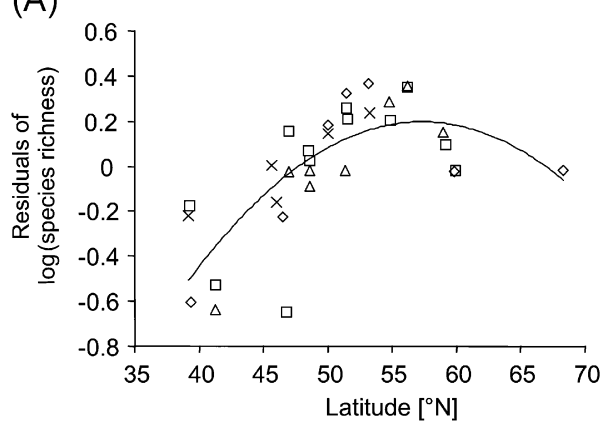

(C)

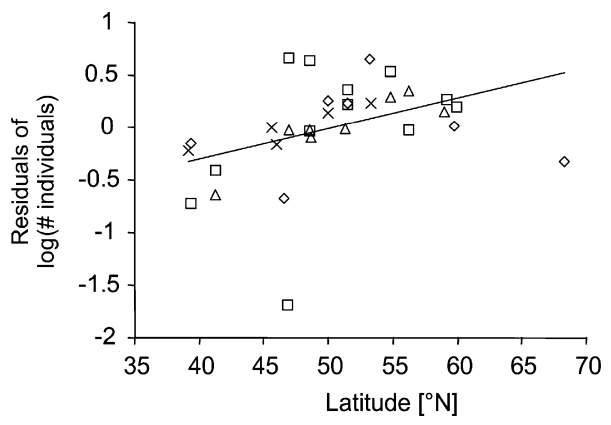

(B)

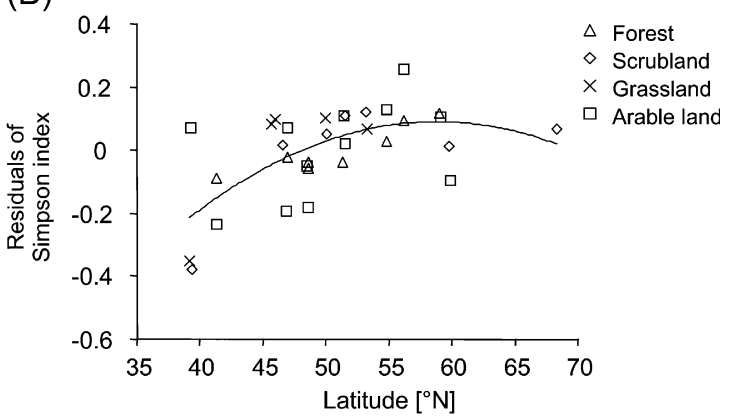

(D)

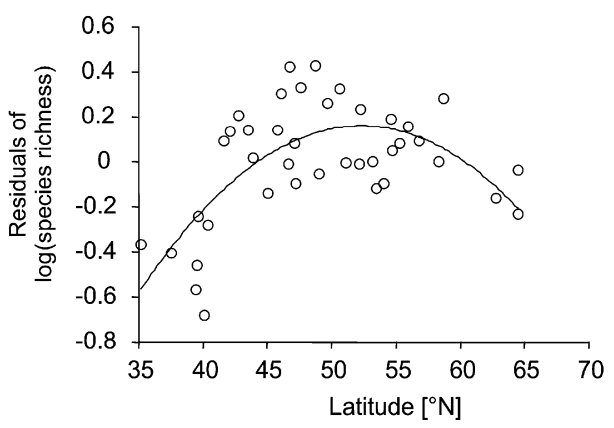

Fig. 3. Correlation of sheetweb spider species richness, Simpson index and activity density with latitude. (A)-(C) show sheetweb spider species, Simpson index and individuals per field site. (D) Shows the known sheetweb spider species per European country. Residuals after accounting for all variables in the final model except latitude are shown. Regression lines are shown for the significant $(p<0.05)$ correlations.

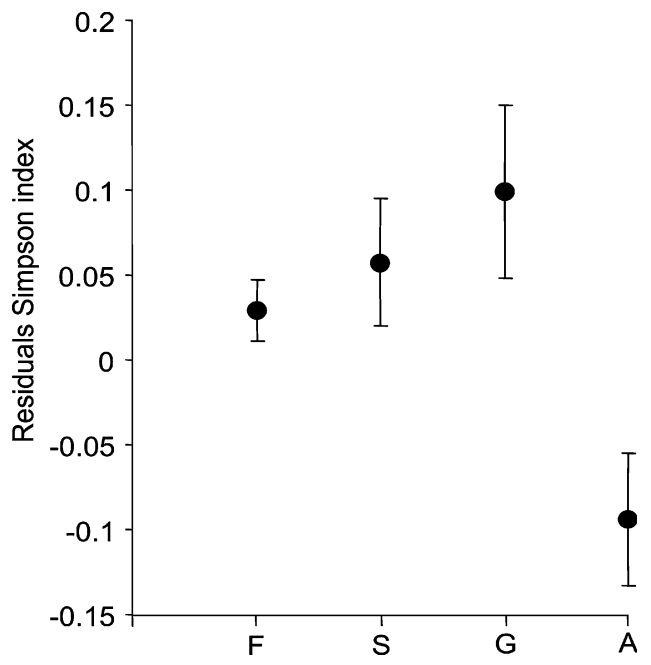

Fig. 4. Diversity (Simpson index) of sheetweb spider assemblages in four types of habitat. $\mathrm{F}=$ forest, $\mathrm{S}=$ scrubland, $\mathrm{G}=$ grassland and $\mathrm{A}=$ arable land. Residuals after accounting for all variables in the model except habitat type are shown. Error bars are standard errors of the mean. There were significant differences between scrubland and arable land $(p=0.032)$ and between grassland and arable land $(p=0.012)$.

sheetweb spider diversity (Fig. $4 ; \quad F_{3,25}=4.74$, $p=0.009$ ). Diversity was lower in arable land than in grassland and scrubland, two less disturbed habitat types.
Activity density of sheetweb spiders increased linearly with latitude $\left(F_{1,26}=4.32, \quad p=0.048 ; \quad\right.$ latitude $^{2}$ : $F_{1,26}=3.54, p=0.071$; Fig. $3 \mathrm{C}$ ), but there was no significant effect of habitat type $\left(F_{3,26}=2.19\right.$, $p=0.113$ ). Also, pairwise comparisons of habitats led to no significant results.

\section{Country inventories}

Species numbers of sheetweb spiders ranged from 16 species each on the Balearic Islands and Crete to 487 species in France. As expected, species richness increased with the surface area of the countries $\left(F_{1,35}=45.97, p<0.001\right)$. As in the local assemblages, species showed a hump-shaped relation to latitude, with a maximum at $52.30^{\circ} \mathrm{N}$ (latitude: $F_{1,35}=27.34$, $p<0.001$; latitude ${ }^{2}: F_{1,35}=24.54, p<0.001$; Fig. 3D). Species richness also responded to square of longitude (longitude ${ }^{2}: F_{1,35}=9.97, p=0.003$ ) with a minimum at intermediate latitudes.

\section{Discussion}

In contrast to spiders in general (Finch et al. 2008), species richness and diversity of sheetweb spiders showed a hump-shaped relationship to latitude with a maximum at $52^{\circ} \mathrm{N}$ and $59^{\circ} \mathrm{N}$ in country inventories and 
habitat samples, respectively. This covers the range from northern Germany, Poland and Belarus to southern Norway and Sweden. The two datasets were qualitatively very similar and there were overall few species in the warm Mediterranean, more species and higher activity densities in the temperate and moderately cool parts of Europe and again lower richness in the cold Scandinavia. Thus, European sheetweb spiders did not share the monotonous increase towards the equator shown by the majority of other study organisms (e.g., Allen, Brown, \& Gillooly 2002; Hawkins et al. 2007; Willig, Kaufman, \& Stevens 2003) but belong to the exceptions (Gaston \& Spicer 1998).

\section{Temperature limitation}

Several mechanisms have been proposed to explain latitudinal biodiversity gradients (e.g., Mittelbach, Steiner, Scheiner, Gross, Reynolds et al. 2001). The majority of studies assume that species richness increases towards the equator because of a higher availability of food and energy. As European sheetweb spiders show different patterns of both species richness and activity density, they are obviously not limited by ambient energy south of about $55^{\circ} \mathrm{N}$ and different mechanisms must be responsible for their decline towards the Mediterranean.

Sheetweb spiders seem to have fewer problems to survive in cold regions than species of other spider families, as they are among the few families of spiders which are active during winter (see Aitchison 1987). Bristowe (1939) also argued that small spiders such as sheetweb spiders might be less restricted to warm temperatures and are therefore found in diverse habitats. Therefore, their potential distribution is greater and their dispersal abilities provide the opportunity to colonize suitable habitats.

\section{Food availability}

The ability of being active during cold periods might also be directly linked with the second assumption of Bristowe (1939) regarding food availability. Sheetweb spiders feed to a relatively large degree on Collembola and nematocerous Diptera. Remarkably, many of these prey groups are winter-active and therefore also active in cold regions (e.g., Aitchison 1983). Together with the good ability of sheetweb spiders to survive in the cold, this could lead to a higher proportion of sheetweb spiders in the north. In addition, it may also lead to a higher activity density and probably higher species richness of sheetweb spiders in northern regions because competition for food is lower as collembolans are too small as prey for many other spiders (Nentwig 1982). This point has been made by Bristowe (1939) already, who argued that these prey species are too small for other adult spider species, and therefore, sheetweb spiders are the only spiders to feed on this prey.

\section{Water limitation}

The water budget can explain why small organisms do better under the cool but moist climate than in the warm and dry Mediterranean. Both, small prey and sheetweb spiders may depend on cool and moist climate because of their small size and correspondingly high risk of desiccation. As already mentioned, sheetweb spiders mostly feed on soft-skinned springtails (Collembola), midges (Diptera) and other small insects (e.g., Harwood, Sunderland, \& Symondson 2004). Some of these prey groups are even more prone to desiccation than sheetweb spiders themselves. Furthermore, springtails move into the litter layer or the soil under dry conditions (J. Zettel, pers. comm.). Their availability as spider prey at the soil surface should thus decrease with increasing drought. The Mediterranean areas, where we found fewer species and lower activity densities than in the north, are characterized by high temperatures and low rainfall in summer, which leads to low soil water content (Fig. 2). In addition, precipitation decreases with increasing continentality. Species richness of sheetweb spider assemblages decreased towards more continental regions, which indicates that aridity is limiting sheetweb spiders.

\section{Limitation by interference}

As another mechanism, the decrease of sheetweb spiders towards warm areas could be caused by an increase of their competitors for food (e.g., Salticidae), as proposed by Enders (1975). Alternatively, also an increased number of antagonists may reduce sheetweb spider richness and density (Jocqué 1984). Sheetweb spiders are relatively susceptible to competition and predation. Sheetweb spider densities are reduced by ants (Sanders \& Platner 2007) and ant abundance increases towards the south (Cushman, Lawton, \& Manly 1993). Also among spider families, sheetweb spiders seem to be relatively weak competitors (e.g., Denno, Mitter, Langellotto, Gratton, \& Finke 2004). Intraguild predation is an important factor structuring spider assemblages (Wise 1993). It is also known that asymmetry in body size promotes intraguild predation and cannibalism (Samu, Toft, \& Kiss 1999) with the larger species often being the intraguild predator (Marshall \& Rypstra 1999). As sheetweb spiders are among the smallest spiders, they are more likely to be killed by other spider families. Therefore, the decline of sheetweb spiders with temperature could also be due to increased densities of superior predators. 
We have shown that sheetweb spider species richness does not increase towards the poles, but starts to decrease again in the north. So there is an increase of sheetweb spider species richness from southern to northern Europe, and an opposite trend starting in Scandinavia. Here, also sheetweb spiders are most likely limited by ambient energy and thereby join the general decrease of organisms towards the arctic.

\section{Dominance structures and habitats}

We observed that species richness and activity density did not differ significantly among the habitat types. The underlying reason might be that long distance dispersal is common in sheetweb spiders, which renders them less dependent on habitat type than species of other families (Marc, Canard, \& Ysnel 1999).

Nevertheless, there were significant differences between two pairs of habitat in the Simpson index. In arable land, Simpson diversity was lower, which indicates higher dominance of a few species than in grassland and scrublands. The reason for this might be that living in a regularly disturbed habitat such as arable land requires special life history strategies, such as synchronization with the periodic disturbances through the timing of reproduction and various dispersal and overwintering strategies (Samu \& Szinetár 2002). Species with such strategies are often called agrobionts and they include several sheetweb spider species. So we can confirm that there are a few species of the sheetweb spiders which are specialized for arable fields and which therefore dominate these locations.

\section{Conclusions}

In both local assemblages and country inventories, sheetweb spider diversity peaked around $55^{\circ} \mathrm{N}$. Towards the north of this peak, they are likely limited by energy availability. Towards the south, water limitation as well as bottom-up and top-down community interactions may reduce sheetweb spiders. So it seems that the sheetweb spiders do not follow the pattern of vertebrates, ants and aquatic organisms, which depend more strongly on energy availability.

\section{Acknowledgements}

Special thanks to Monica Wyss-Lopez for logistic support and sharing of climate data and all field workers for operating traps. We further thank Anna Stäubli and Ambros Hänggi for their help with spider determination. The ALARM Field Site Network was coordinated by Koos Biesmeijer and Bill Kunin. Timothy D.
Mitchell provided the CRU 2.1 gridded climate data set. FSN is funded by the EC within the FP 6 Integrated Project ALARM (Assessing LArge scale environmental Risks for biodiversity with tested Methods; GOCE-CT2003-506675; www.alarmproject.net).

\section{Appendix A. Supplementary Material}

The online version of this article contains additional supplementary data.

\section{References}

Aitchison, C. W. (1983). Low temperature and preferred feeding by winter-active Collembola (Insecta, Apterygota). Pedobiologia, 25, 27-36.

Aitchison, C. W. (1987). Feeding ecology of winter active spiders. In W. Nentwig (Ed.), Ecophysiology of spiders (pp. 264-273). Berlin: Springer.

Allen, A. P., Brown, J. H., \& Gillooly, J. F. (2002). Global biodiversity, biochemical kinetics, and the energetic-equivalence rule. Science, 297, 1545-1548.

Bristowe, W. S. (1939). The comity of spiders. 2 Vols. London: Ray Society.

Cardoso, P., Silva, I., De Oliveira, N. G., \& Serrano, A. R. M. (2007). Seasonality of spiders (Araneae) in Mediterranean ecosystems and its implications in the optimum sampling period. Ecological Entomology, 32, 516-526.

Colwell, R. K., Mao, C. X., \& Chang, J. (2004). Interpolating, extrapolating, and comparing incidence-based species accumulation curves. Ecology, 85, 2717-2727.

Cushman, J. H., Lawton, J. H., \& Manly, B. F. J. (1993). Latitudinal patterns in European ant assemblages: Variation in species richness and body size. Oecologia, 95, 30-37.

Denno, R. F., Mitter, M. S., Langellotto, G. A., Gratton, C., \& Finke, D. L. (2004). Interactions between a hunting spider and a web-builder: Consequences of intraguild predation and cannibalism for prey suppression. Ecological Entomology, 29, 566-577.

Enders, F. (1975). The influence of hunting manner on prey size, particularly in spiders with long attack distances (Araneidae, Linyphiidae, and Salticidae). American Naturalist, 109, 737-763.

Finch, O. D., Blick, T., \& Schuldt, A. (2008). Macroecological patterns of spider species richness across Europe. Biodiversity and Conservation, 17, 2849-2868.

Fox, J. (2009). car: Companion to Applied Regression. R package version 1.2-12. 〈http://www.r-project.org $\rangle$, $\langle$ http://socserv.socsci.mcmaster.ca/jfox/ $\rangle$.

Gaston, K. J., \& Spicer, J. I. (1998). Biodiversity. An introduction. Oxford: Blackwell.

Harwood, J. D., Sunderland, K. D., \& Symondson, W. O. C. (2004). Prey selection by linyphiid spiders: Molecular tracking of the effects of alternative prey on rates of aphid consumption in the field. Molecular Ecology, 13, $3549-3560$. 
Hawkins, B. A., Albuquerque, F. S., Araújo, M. B., Beck, J., Bini, L. M., Cabrero-Sañudo, F., et al. (2007). A global evaluation of metabolic theory as an explanation for terrestrial species richness gradients. Ecology, 88, 1877-1888.

van Helsdingen, P. J. (2007). Araneae. In Fauna Europaea database (version 2007.1). 〈http://www.european-arachnology.org $>$.

Hickler, T., Fronzek, S., Araújo, M. B., Schweiger, O., Thuiller, W., \& Sykes, M. T. (2009). An ecosystemmodel-based estimate of changes in water availability differs from water proxies that are commonly used in species distribution models. Global Ecology and Biogeography, 18, 304-313.

von Humboldt, A. (1808). Ansichten der Natur mit wissenschaftlichen Erläuterungen. Tübingen: J.G. Cotta.

Jocqué, R. (1984). Considérations concernant l'abondance relative des araignées errantes et des araignées à toile vivant au niveau du sol. Revue Arachnologique, 5, 193-204.

Lande, R. (1996). Statistics and partitioning of species diversity, and similarity among multiple communities. Oikos, 76, 5-13.

Marc, P., Canard, A., \& Ysnel, F. (1999). Spiders (Araneae) useful for pest limitation and bioindication. Agriculture Ecosystems and Environment, 74, 229-273.

Marshall, S. D., \& Rypstra, A. L. (1999). Spider competition in structurally simple ecosystems. Journal of Arachnology, 27, 334-350.

Mitchell, T. D., \& Jones, P. D. (2005). An improved method of constructing a database of monthly climate observations and associated high-resolution grids. International Journal of Climatology, 25, 693-712.

Mittelbach, G. G., Steiner, C. F., Scheiner, S. M., Gross, K. L., Reynolds, H. L., Waide, R. B., et al. (2001). What is the observed relationship between species richness and productivity? Ecology, 82, 2381-2396.

Mönkkönen, M., Forsman, J. T., \& Bokma, F. (2006). Energy availability, abundance, energy-use and species richness in forest bird communities: A test of the species-energy theory. Global Ecology and Biogeography, 15, 290-302.

Nentwig, W. (1982). Epigeic spiders: Their potential prey and competitors: Relationship between size and frequency. Oecologia, 55, 130-136.

Nentwig, W., Hänggi, A., Kropf, C., \& Blick T. (2003). Central European spiders-determination key. 〈http://www.araneae.unibe.ch $>$.
Platnick, N. I. (2008). World spider catalog, version 8.5. American Museum of Natural History. 〈http://research. amnh.org/entomology/spiders/catalog/INTRO1.html $\rangle$.

R Development Core Team. (2006). R: A language and environment for statistical computing. $\mathrm{R}$ foundation for statistical computing: Vienna, Austria. 〈http://www. R-project.org >.

Rötzer, T., \& Chmielewski, F. M. (2001). Phenological maps of Europe. Climate Research, 18, 249-257.

Samu, F., \& Szinetár, C. (2002). On the nature of agrobiont spiders. Journal of Arachnology, 30, 389-402.

Samu, F., Toft, S., \& Kiss, B. (1999). Factors influencing cannibalism in the wolf spider Pardosa agrestis (Araneae, Lycosidae). Behavioral Ecology and Sociobiology, 45, 349-354.

Sanders, D., \& Platner, C. (2007). Intraguild interactions between spiders and ants and top-down control in a grassland food web. Oecologia, 150, 611-624.

Settele, J., Hammen, V., Hulme, P., Karlson, U., Klotz, S., Kotarac, M., et al. (2005). ALARM: Assessing large-scale environmental risks for biodiversity with tested methods. Gaia - Ecological Perspectives for Science and Society, 14, 69-72.

Smith, B., Prentice, I. C., \& Sykes, M. T. (2001). Representation of vegetation dynamics in the modelling of terrestrial ecosystems: Comparing two contrasting approaches within European climate space. Global Ecology and Biogeography, 10, 621-637.

Stephens, P. A., Buskirk, S. W., \& Martínez Del Rio, C. (2006). Inference in ecology and evolution. Trends in Ecology and Evolution, 22, 192-197.

Sykes, M. T., Prentice, I. C., \& Cramer, W. (1996). A bioclimatic model for the potential distributions of North European tree species under present and future climates. Journal of Biogeography, 23, 203-233.

Ter Braak, C. J. F., \& Smilauer, P. (2002). CANOCO reference manual and CanoDraw for Windows user's guide: Software for canonical community ordination (version 4.5). Ithaca, NY, USA: Microcomputer Power.

Venables, W. N., \& Ripley, B. D. (2002). Modern Applied Statistics with S. Fourth Edition. Springer, New York.

Willig, M. R., Kaufman, D. M., \& Stevens, R. D. (2003). Latitudinal gradients of biodiversity: Pattern, process, scale, and synthesis. Annual Review of Ecology, Evolution, and Systematics, 34, 273-309.

Wise, D. H. (1993). Spiders in ecological webs. Cambridge, England: Cambridge University Press. 